\title{
Colin KOOPMAN, Pragmatism as transition. Historicity and Hope in James, Dewey, and Rorty
}

Columbia University Press, New York, 2009

\section{Roberto Frega}

\section{(2) OpenEdition}

Electronic version

URL: http://journals.openedition.org/ejpap/976

DOI: 10.4000/ejpap.976

ISSN: 2036-4091

\section{Publisher}

Associazione Pragma

Electronic reference

Roberto Frega, «Colin koopman, Pragmatism as transition. Historicity and Hope in James, Dewey, and Rorty », European Journal of Pragmatism and American Philosophy [Online], I-1/2 | 2009, Online since 01 July 2009, connection on 24 September 2020. URL : http://journals.openedition.org/ejpap/976 ; DOI : https://doi.org/10.4000/ejpap.976

This text was automatically generated on 24 September 2020

\section{(c) (i) (9)}

Author retains copyright and grants the European Journal of Pragmatism and American Philosophy right of first publication with the work simultaneously licensed under a Creative Commons AttributionNonCommercial-NoDerivatives 4.0 International License. 


\section{Colin KoOPMAN, Pragmatism as transition. Historicity and Hope in James, Dewey, and Rorty}

Columbia University Press, New York, 2009

Roberto Frega

\section{REFERENCES}

Colin Koopman, Pragmatism as transition. Historicity and Hope in James, Dewey, and Rorty,

Columbia University Press, New York, 2009

1 Koopman's book revolves around the notion of transition, which he proposes is one of the central ideas of the pragmatist tradition but one which had not previously been fully articulated yet nevertheless shapes the pragmatist attitude in philosophy. Transition, according to Koopman, denotes "those temporal structures and historical shapes in virtue of which we get from here to there" (2). One of the consequences of transitionalism is the understanding of critique and inquiry as historical processes. The term transitionalism is the term of art Koopman chooses for identifying the historicist attitude of the pragmatist mode of thinking. With his book, Koopman aims at bridging the gap he sees between the classical - mostly Deweyan and Jamesian - version of pragmatism and the second wave of pragmatism - in particular, the Rortyan version. The banner under which Koopman proposes to understand pragmatism as a unified stream going from Peirce to Brandom (via James, Dewey, Rorty, and Putnam) is that of philosophy as "meliorist cultural criticism." A definition, we should note, which perfectly suit - and this is by no means by chance - James' and Rorty's philosophies. Transitionalism so conceived, in fact, is not simply a philosophy or metaphysics of history, nor in the Foucauldian vein, an ontology of history. Transitionalism express rather the conception of temporality implicit in the melioristic attitude shared by the pragmatist tradition: pragmatism, to that extent, is transitional because it is 
melioristic: it sees time as the sphere where transformations can be brought about and improvement achieved.

2 The aim of the book is twofold: firstly, to articulate the concept of transitionalism; secondly, to show how this theme runs through the pragmatist tradition and the extent to which it can bind together all its scattered strands. In this vein, Koopman offers us sketches of transitional epistemology, ethics, politics, and, as an open conclusion, a hint towards a rapprochement of pragmatist transitionalism and the genealogical tradition.

3 Transitionalism as Koopman proposes us to conceive it, is built upon the melioristic intuition, that Koopman urges us to acknowledge as the motivating inspiration of all the pragmatist tradition. The transformative attitude implicit in meliorism requires that we operate in a frame that is that of intentional and directed change: from worse to better. If we see pragmatism in this guise, it is clear why Koopman urges us to gather all pragmatist efforts under the label of transitionalism. Pragmatism as transitionalist places us in the middle of things (or better, of situations) and, from that vantage point, urges us to think comparatively: in a melioristic perspective, the focus is never on what is true, good, or just, but on how a present situation can be improved: how a belief can be made sounder, how a moral situation bettered, how the level of justice improved. Meliorism, to this extent, generalizes upon Dewey's ethical (but broadly philosophical) maxim that "growth is the only end in itself", or James' "life is in the transition" (this last quoted by Koopman, 12). Any fallibilistic epistemology, to that extent, might be termed 'transitional', as well as any ethical, political (or other) philosophy that conceives human processes of development as being open ended.

4 According to the transitionalist approach, "philosophy is best understood as a theory and practice of hopeful cultural criticism" (16). This cultural criticism presupposes hope as the motivating force: we engage in criticism because we hope that in that way we will ameliorate the present situation. To that extent, the melioristic approach presupposes an attitude of hope, which in turn is tied to pluralism (multiple worlds exist) and humanism (humans contribute to the worlds they inhabit). The world is in transformation, and humans take part to this process and, to a certain extent, can control it. Pragmatism is committed to the thesis that we can create better world and selves. This, according to Colin Koopman, is the central thesis of the pragmatist tradition.

5 Koopman - and this is one of the most important thesis of his book - believes that this ground offers an ecumenical perspective capable of bringing all the different strands of pragmatism (classical and neo) under a new 'third wave' synthesis.

6 The second chapter retraces the transitionalist theme to most of the classical and contemporary pragmatists, including thinkers such as Peirce and Quine. The aim is to show the extent to which this theme is present in the pragmatist tradition, even outside those figure whose transitionalist commitment is clear. Transitionalism is originally developed by Emerson and pass successively on to James and Dewey. This, in Koopman intentions, should count as a demonstration of the fact that the category of transitionalism can sustain the theoretical work needed in order to bring all the pragmatist tradition under a single umbrella. While interesting, this reconstruction underscores the shaping force of evolutionism, whose inspiration is explicitly at work in any deweyan (and many peircean) attempts at defining the temporal structure of human experience. Transition, change, novelty (52) are also central categories of any 
evolutionary approach. To better defend the transitional paradigm, more detailed historical analysis would be required in order to distinguish the melioristic from the evolutionary theme in the different philosophies. Moreover, as it will become clear in the following chapters, the commitment of the pragmatists to the melioristic assumption is so differentiated in tone and degree that when Koopman tries to articulate its epistemological, ethical, and political implications, he will be obliged to get rid of Peirce and Quine, to set aside Putnam and Margolis, and grossly misinterpret Dewey, to the extent that at the end of his journey what remains in the hands of the third wave pragmatists is the affinity among James and Rorty as thinkers of hope.

That things would have gone that way the reader can feel it since the first chapter, where Koopman lay out as the epistemological pillar of his project is James' theory of truth. I will only remark in passing that James' insights into epistemology could have been defended more easily if they were discussed in a way not so totally oblivious of a century of speculation in logic and epistemology. This starting point, inevitably, drives Koopman to a gross misunderstanding of Dewey and Peirce epistemologies. He not only dismisses Peirce as an inspiring source of his transitional pragmatism (and this brings to zero his chances to "to integrate what is best in the two distinctive waves of pragmatist thought that have preceded it," 3), but his appraisal of Dewey is paid at the too high cost of getting rid of his epistemology in order to make of him that critic of culture that Rorty wanted him to be. Many scholars will be astonished in reading that for Dewey "truth might be but one of the names for our self-salving" (43). But more is to come for those who take Peirce seriously and those who do not read Dewey after Rorty. A not small portion of people interested in pragmatism, I believe.

The chapter devoted to the articulation of a transitional epistemology opens with the acknowledgment that one of the main epistemological innovations developed by pragmatism concerns the introduction of temporality into epistemic relations. According to pragmatism, knowledge is conceptualized as a historical relation between former expectations and subsequent consequences (practical eventualities). It is a definition broad enough to encompass pragmatists from Peirce to Rorty, and it is limited enough to usefully describe the pragmatist epistemology as opposed to different epistemological projects. Our practical engagements with the world stand as starting point of the epistemological work. The historical, sociological and anthropological conditions that qualify a given context are considered the inescapable reference of all epistemic acts. Then Koopman accomplishes a further step that reproduces the divide between those pragmatists that consider normativity a necessary part of epistemology (here I would list Peirce, Dewey, Margolis, Putnam) and those that consider that historicity replaces normativity (here I would list James and Rorty). Both camps (at least some of their participants) will acknowledge the inescapability of contextual elements in the production of knowledge as a temporal process, but while the first group will urge that this fact changes our understanding of normativity - a normativity free of universalistic pretences, the second would simply dismiss the need for a normative enterprise. Claiming that "epistemic success and failure are internally attributed wholly within practices" (111, my emphasis), Koopman sides explicitly with the second group. It should be noted that none of the philosophers I put in the first group would agree to such a claim, unless specifications are offered that grant a specific place for normativity. As a paradigmatic exemplification of his transitional epistemology, Koopman offers the sociological work of Pierre Bourdieu, whose conception of practice is surely in line with the pragmatist outlook, but whose work is 
surely not a pertinent source for epistemology. Koopman is well aware of the objections that even pragmatists (of the first stripe) could move to his claim. He firstly reminds us that pragmatist epistemology refuses the spectator theory of knowledge and, in so doing, reclaimed the right of practice in the field of epistemology. Overcoming correspondence, coherence and proceduralist conceptions of truth, pragmatism paves the way for this epistemological role of practice. This surely accounts for the epistemological revolution brought about by pragmatism and constitute the common ground of most of the epistemological outlooks that traceable to pragmatism. Historical, sociological, and anthropological approaches are required in order to reconstruct the different ways human beings have developed in order to fix their beliefs. This, again, is a claim that most pragmatists would accept, and can be put at the basis of a general pragmatist epistemology. But the question remains open whether and how we could discriminate between competing ways (methods) of belief fixation. It is precisely on this point that the pragmatist tree splits in different and non reconcilable directions and that Koopman has to take side: he cannot have both in his group Peirce and James, Dewey and Rorty, Margolis and Bourdieu. To this extent, his transitional epistemology cannot function as a pragmatist koiné, and is forced to reproduce instead of solving - those philosophical conflicts that since Peirce's and James' time characterize the philosophical conversation inside pragmatism. Koopman is fully right in reminding us that the pragmatist epistemology was born "in the crucible of probabilities" (113). But we should not forget that probable reasoning gives rise to two different strategies: the betting strategy that Koopman adopts in order to define the pragmatist-transitionalist conception of inquiry, and the abductive strategy, according to which rather than betting we accurately assess arguments, compare results, engage with experience. A bet, like the Pascal wager so dear to James takes place where reason offers no more evidence, while abduction takes place precisely as an act of reason. The second is controlled, the first relies on will. Beliefs, Peirce and Dewey said, are hypotheses, not bets. The epistemological and practical difference stands here as an irreducible divide. Of course, bets are not blind, but there are nevertheless limitations to the validity of the metaphor, and words are never chosen by chance.

9 A similar strategy drives his effort at defining a transitional approach to ethics. He opens his chapter on this topic with a notion that some would consider an oxymoron and others would refuse with force: that of a perfectionist pragmatism. The background of this approach is given by the idea that the dominant moral doctrines of deontology and teleology should be overcome and that cannot be done by virtue ethics. Perfectionist pragmatism is advanced precisely as a solution to this diagnosis.

Claiming a perfectionist tone for pragmatism, Koopman sides obviously against Cavell, whose understanding of pragmatism and perfectionism posits an incompatibility between the two terms. According to Koopman, such an understanding is wrong because based upon a reductive conception of pragmatism (the same he will use in interpreting Dewey). Koopman strongest argument for advocating a perfectionist tone for pragmatism is to rely on its melioristic attitude: meliorism is, for Koopman, a sure sign of perfectionism, as both share a tension towards perfecting the self. In this enterprise, Koopman assigns to James rather than Dewey the leading role. In following Cavell, Koopman considers perfectionism as not refusing but rather including teleology and deontology. The same, Koopman claims, is true of pragmatist ethics. Although it is not very clear why reference to will and pleasure should imply the endorsement of deontology and teleology, Koopman clearly identifies in the process of perfecting and 
in the refusal of a rule-based ethics a common theme of pragmatism and perfectionism. In James' notion of effort Koopman finds another perfectionist notion: while pragmatist meliorism does not necessarily depend upon an ethic of the effort, the Jamesian version proposes such a connection, and sides Emerson's perfectionism in emphasizing the crucial importance of individual acts of discontinuity in facing radical moral situations. On this side, too, Koopman's proposal is more Jamesian than Deweyan, so confirming an interpretive line joining Emerson, James, and Rorty. Although I am not sure that Cavell would be satisfied by Koopman's answer (acknowledging the necessity to combine acceptance of the given conditions - principle of moral pleasure - and will to transform them - principle of will - does not seem to satisfy adequately Cavell's criteria for perfectionism), the articulation of these two criteria offers a starting point for defining a progressive and melioristic attitude in ethics such as that can be found at the bottom of some pragmatist philosophies.

11 The chapter on politics follow the same scheme that structures that on ethics, only replacing deontology and teleology with utopianism and dystopianism as the contemporary political philosophies that pragmatism is supposed to replace. Among the rationalistic utopian approaches, Koopman includes Rawls'. Among the irrationalistic, dystopian thinkers, Koopman lists Benjamin, Heidegger, Derrida, and Zizek.

12 This frame is meant at drawing an opposition between over-rationalistic approaches that disregard the specific traits of political reality in order to follow only the idealities of reason, and irrationalistic and pessimistic approaches that focus exclusively on a reality considered as irremediably compromised with power and incapable of offering any reason for hope. The pragmatist move consists here, as in the field of ethics, in delineating an intermediate path, capable of bringing ideality and reality to terms. Pragmatism so conceived, in fact holds "that political reason is always situated within a context but in such a way as to provide the resources for its own improvement" (164). Surprisingly, Koopman tells us that this move approaches pragmatism to conservative thinking, namely to those conservatives "who articulate evolutionary, developmental, and situate conceptions of political practice." This is puzzling at the highest degree: not only there is no valid reason for associating conservative with evolutionary and developmental arguments in political theory, on the contrary. But the association of pragmatism and conservatism is even more surprising, especially as this is justified because of a supposedly common engagement with reformism instead as revolutionism. That "we ought not flee from political reality in order to engage an ethical perspective" (164) seems to be at least a very inventive conception of conservatism. Nevertheless, if we leave aside this very unhappy categorization of political theories, what remains is a steady affirmation of a contextual principle. We are brought again back to that primacy of practice that characterizes pragmatist philosophies. Drawing on Dewey's political philosophy, Koopman proposes to define a melioristic approach to politics "as the improvement of political realities on the basis of resources already available within the very realities on which we are working" (167). Here Koopman re-proposes the model of an absolute immanence, of a pure historicity in which situation, practice, or context cannot and need not be transcended in order to successfully act inside them. Situations and every kind of context are considered to be already provided of those normative criteria which are required in order to discriminate growth from its opposite: "we need not, nor could we ever hope to, transcend the present situations in which we find ourselves in order to locate the 
resources we need for meliorating that situation" (168). A definition that, once again, would better suit Rorty's dismissal of epistemology and James' will to believe than Dewey's affirmation of the normative requirements of inquiry. The following paragraph traces parallels between this melioristic conception of politics in pragmatism and analogous conceptions in Williams', Foucault's, Young's, and Sen's political philosophies, underlying their common endorsement of the principle of the primacy of practice. Of these, the melioristic reading of Williams' philosophy is particularly insightful.

In his concluding chapter, Koopman proceeds to trace a pathway aimed at bringing pragmatism near to genealogical thinking, on the basis of their common usage of the knowledge of the past for gaining guidance in the present and in the future. The use of history recommended by Koopman to pragmatism is genealogical in sort: it is a use of history aimed at understanding the processes through which we have become what we presently are. We are not far, as soon Koopman will explain, from Foucault's project of an historical ontology. The pragmatist paradigm chosen in order to highlight pragmatism's compatibility with genealogy is Dewey's reconstructive model of inquiry. Koopman interprets Dewey's injunction to place inquiry into the context of problematic situations as a call for philosophers to recur to social and historical sciences in order to deepen their understanding of practices on which they reflect. He completes his interpretation of reconstruction as the core of deweyan pragmatism adding that it proceeds on the basis of resources already present in the situation (principle of absolute immanence) and is intrinsically an ameliorative process. He then proceed, on the basis of a model he has applied in former chapters, to contrast this conception of thinking to more traditional conceptions - here what he terms realism and idealism, in order to show that pragmatism constitutes a third way that draws upon their resources but in order to frame a new conception. This is the only place where Koopman deeply tackles Dewey's philosophy, engaging in a critical assessment of Dewey's theory of inquiry. This last is heavily criticised for not having adequately explained how problematic situations are generated, because of an exclusive focus on their resolution. In the several pages devoted to Dewey, we find lots of very trenchant judgments such as: "Dewey simply had too little to say about how we might fashion forms of inquiry that help us bring the right kinds of problems into focus" (199). This is a bit too fast, especially as what is offered as evidence for such a critique are only few quotes disparagingly taken from different texts. Koopman should have better taken a deeper look at Dewey's pedagogical and political writings, where we find accurate diagnosis of obstacles, constraints, causes that hinders political and educative practice. Or to his conception of the qualitative as the process through which the indeterminate situation becomes determinate. It is certainly true that Dewey did not provide detailed social analysis of reality, but this was not the focus of his research. It is astonishing that in his search for a general theoretical paradigm, Koopman does not see the fruitfulness of Dewey's theory of inquiry as an abstract description of the general process of how problems arise, are perceived, transformed through inquiry, faced, solved. His criticism of his conception of the notion of situation is based upon a very reductive reading of his texts (Burke, Dewey's new logic showed that in great details fifteen years ago, Sleepers, The Necessity of Pragmatism more than twenty years ago). Then, of course, the role of other traditions and approaches in the analysis of psycho-socio-politicaleconomical-gender, etc. factors that contribute in shaping problematic situations is certainly of great and irreplaceable value. In this sense, and hopefully, sixty years of 
philosophy and social sciences has not passed in vain. The same treatment, not surprisingly, is then offered to Peirce, whose epistemology is too easily dismissed without even considering the potentialities implied not only in the doubt-belief paradigm, but even in Peirce's complex conception of the practice of research and of how subtle and complex is the experience of doubt in different forms of inquiry. To say that for Dewey and Peirce doubt is "an unanalyzable given state of mind" or a form of givenness that "do not stand in need of explication, justification, interpretation, or inferential articulation" (205) is simply a proposition so off the mark that no Peirce of Dewey scholar can take seriously.

In the end, which is the global contribution of Koopman's project to the advancement of pragmatism? A first remark is that, his statements notwithstanding, his account of pragmatism is decidedly not ecumenical but steadily biased towards a JamesianRortyan understanding. While it is pretty clear that his melioristic and transitional concerns fit poorly with Peirce's vision (and practice) of philosophy, and with the epistemological outlooks it inspired (and which are still living and well inside the pragmatist tradition). It also tends to deeply misread Dewey, bringing him selectively towards the Rortyan reading. One of the unhappy consequences of this rehearsing of Rorty's interpretation of Dewey is a misunderstanding of the force and novelty of Dewey's epistemology and the rehearsal of a interpretative canon that prioritizes the image of Dewey critic of culture and thinker of reform and reconstruction over an image of Dewey where his evolutionary and epistemological sensibility find their proper place (Dewey as a theorist of rationality, as the inventor of an original theory of judgment, as bringing science into the evolutionary mould, etc.). This is a move many other have accomplished - especially after Rorty's lesson, but is a move that has also been deeply criticised and that I think should be resisted. For these and similar reasons, his proposed definition of the pragmatist movement under the label of "transitionalism" is too narrow for his scope. But could have it been otherwise? Bringing Emerson and Peirce (under Rortyan auspices) under the same umbrella is simply a too hard task, unless the chosen umbrella is so broad to become irrelevant. According to Peirce and (to a great extent) Dewey, philosophy is simply NOT a critique of culture, although philosophers could (and for Dewey probably should) engage ALSO in the critique of culture.

And this is the second risk that Koopman enters: his transitional philosophy, aptly inspired by non pragmatist thinkers such as Iris Marion Young and Michel Foucault, is in a way too broad to serve the purpose: as a kind of historicism, transitionalism apply to too many thinkers to be aptly used for defining a single tradition of thought, i.e. pragmatism (be it its third wave). If, following Koopman, we consider that "philosophy is best understood as a theory and practice of hopeful cultural criticism" (16), and if we define meliorism as the will to contribute to the "epistemic, ethic and political realities in which we find ourselves flowing", which philosopher, scientist, or practitioner would deny to adhere to the melioristic claim? Is not any research by default engaged in bettering the epistemic condition of his discipline? His not any practitioner or sociopolitical theorist engaged - at least provisionally - in improving the ethical, social, and political conditions of his time? Wouldn't we say that even of non pragmatist thinkers such as John Rawls? Meliorism and transitionalism so conceived are probably best conceived as the signs of our time: a time of increased degrees of transformation, of generalized experimental and fallibilistic approaches to reality, of extraordinarily shortened life-cycles for any product, idea, institution produced by humans. 
Pragmatism, with the works of Dewey and James, has surely been one of the first philosophical traditions to interpret this new configuration of human societies (but let's not forget Marx's famous claim that in capitalist societies "all that is solid melts into airs"). In this, pragmatism was of course indebted to the fluxive interpretation of nature offered by the Darwinian revolution. After that, many philosophers and scientists have attempted to articulate this evolutionary and progressive outlook in different guise, so giving rise to a transitional way of thinking (surely in tone with a society increasingly based on dynamical processes of change at all levels).

For these reasons, I think that the ecumenical project of overcoming the opposition of classic and neo pragmatist in the 'new synthesis' of a third wave of transitional pragmatism fails: we hardly needed Koopman to acknowledge the similarities between James and Rorty, and the debate between those that consider Rorty a follower of Dewey and those that consider him a 'traitor' won't be close by this book. Moreover, there will be no 'peace' as he puts it, simply leaving Peirce (and the part of Dewey's thinking much indebted to him) outside the group. What Koopman proposes here as a 'new synthesis,' is probably no more that the furthering of a fruitful and well established line of interpretation in the pragmatist tradition, going from Emerson to Koopman himself via James, McDermott, Rorty, Stuhr and many other classical and contemporary philosophers. Along this line, Koopman's is surely an interesting book that pushes the fringes of the pragmatist tradition a bit further.

\section{AUTHORS}

\section{ROBERTO FREGA}

CNRS Paris

fregarob@gmail.com 